\title{
Methods and demographic findings of the baseline survey of the NEDICES cohort: a door-to-door survey of neurological disorders in three communities from Central Spain
}

\author{
J.M. Morales ${ }^{a, *}$, F.P. Bermejo ${ }^{b}$, J. Benito-León ${ }^{c}$, J. Rivera-Navarrod, \\ R. Trincado ${ }^{b}$, R. Gabriel $S^{e}$, S. Vega ${ }^{f}$, NEDICES Study Group ${ }^{g}$
}

${ }^{a}$ Department of Research, Ministry of Labour and Social Affairs, Madrid, Spain

'Department of Neurology, University Hospital '12 de Octubre', Madrid, Spain

${ }^{\mathrm{C}}$ Department of Neurology, Móstoles General Hospital, Madrid, Spain

${ }^{\mathrm{d}}$ Area for Applied Epidemiology, National Centre for Epidemiology, Institute of Health Carlos III, Madrid, Spain

'Section of Clinical Epidemiology, University Hospital 'Princesa', Madrid, Spain

${ }^{\mathrm{f}}$ Arévalo Health Centre, Arévalo, Segovia, Spain

${ }^{\mathrm{g}}$ The NEDICES (Neurological Disorders in Central Spain) Study Group. Main investigators of the three locations: Margaritas, FBP; Lista, RGS; Arévalo, SVQ. Main investigator of the WHO-AAD Project: Alberto Portera-Sánchez. Neurologists: Jaime Díaz, Cristina Fernández, JA Molina S, Javier Olazarán, Javier Rodríguez, JBL and FBP. Supervisors: Fernando Pérez del Molino, JRN, Margarita Alonso, Candelas Gómez and Carmen Saiz. Informatics: Guillermo Fernández J. Statistical analysis: RT and Paz Rodríguez.

Epidemiologists: JMM and RGS.

Received 16 April 2003; received in revised form 22 September 2003; accepted 20 October 2003 Available online 25 March 2004

KEYWORDS
Epidemiological
methods; Health surveys;
Geriatric assessment;
Older people;
Neurodegenerative
diseases; Stroke

Summary Objective: To describe the methods and general results of the baseline longitudinal survey in a defined cohort of elderly people from three areas of Central Spain (urban and rural). The survey was designed to study dementia, essential tremor, Parkinson's disease and stroke.

Study design: A population-based longitudinal study with door-to-door interviews. Methods: This study was carried out in two phases: Phase 1 (health status questionnaire and screening performed by lay interviewers) and Phase 2 (diagnosis of neurological illnesses by neurologists).

Results: The study flow chart, screening instruments for neurological disorders, main demographic data (age, sex, educational attainment, occupation) and general health status of the 5278 screened participants ( 2238 men and 3040 women) are given for the two phases. The response rate was $85.3 \%$, and participation was higher in men and in the urban area.

Conclusions: Participation rates were good in both phases of the NEDICES baseline study, and this was influenced by age, sex and setting of the participants. Educational attainment, occupation and health status data are analogous to other Spanish studies performed in the elderly. As the study population was large and good participation rates were achieved, precise analysis of morbidity of the neurological disorders investigated will be possible.

(C) 2004 The Royal Institute of Public Health. Published by Elsevier Ltd. All rights reserved. 


\section{Introduction}

Several population-based studies investigating neurological disorders in the elderly have been performed recently in Spain. ${ }^{1-9}$ However, these studies had relatively small population samples (less than 1500 people) and they evaluated singlesite populations. Between 1994 and 1995, a largescale survey was performed to obtain an elderly Spanish cohort, in whom health status will be estimated, in addition to morbidity (prevalence and incidence rates) and mortality rates of agerelated cardiovascular and neurological diseases.

The NEDICES cohort was carried out in two phases (screening and diagnosis) according to the rules of a population-based survey in rare diseases, in which specialists are required to make differential diagnoses in a large sample. ${ }^{10}$

The NEDICES study was based on two previous projects: the World Health Organization Age-Associated Dementia project (WHO-AAD) ${ }^{11}$ and the EPICARDIAN study. ${ }^{12}$ Other aspects were included for assessing caregivers' needs. Spanish participation in the WHO-AAD project was mainly for the validation of dementia screening tests. The EPICARDIAN study was designed to investigate cardiovascular diseases and their risk factors. The NEDICES study selected three geographical areas to obtain a cohort of elderly people dwelling in one well-defined area of Spain (Central Spain), but with different cultural and socio-economic backgrounds. The main aim of this longitudinal project was to analyse the prevalence and incidence rates of neurological diseases (stroke and transient ischaemic attack syndrome (TIA), dementia, Parkinson's disease (PD) and essential tremor) over a 3-year period.

In this paper, we describe the planning and methods of this large-scale survey, and report the demographic findings of the NEDICES cohort.

\section{Methods}

\section{Geographical areas}

Three communities of central Spain were studied, two urban and one rural. The first urban site was the district of 'Margaritas' in Getafe $(170,000$ inhabitants, $15.5 \%$ over 65 years of age), a suburb of metropolitan Madrid composed mainly of working-class people. The second urban site was the 'Lista' area in a central district of Madrid (approximately 150,000 inhabitants, $16.5 \%$ over 65 years of age), composed mainly of people of medium or medium-high income (professionals and white-collar employees). The rural location was in Arévalo county, comprising 38 small villages $(9000$ inhabitants, $24 \%$ over 65 years of age) around Arévalo town (Ávila), situated $125 \mathrm{~km}$ north-west of Madrid. The population is mainly agrarian.

These three sites were chosen according to the following criteria: (a) approximately 2000 elderly inhabitants; (b) existing computer-based registries of elders' medical data in the primary physicians' setting; and (c) a close relationship between the NEDICES group and the local physicians and health authorities. Moreover, these sites have sufficient differences in social structures to allow study of elderly samples with different lifestyles and risk factors of cerebrovascular diseases.

In each municipality (Getafe for Margaritas, Salamanca district for Lista, and Arévalo), the local registry office (LRO) maintains a regularly updated population register that includes information about sex, date of birth, address and level of formal education. The survey frame was a list of all residents on 31 December 1993 taken from the LRO. All people over 64 years of age were considered to be eligible for the study if they were resident in the area on 31 December 1993 or if they had been resident in the area for six or more months in 1993. The survey covered the household and nursing home populations of the three communities. Eligible subjects living in institutions outside the study areas were not included due to budgetary restrictions.

\section{Prevalence estimation}

Point prevalence was used to measure disease frequency, and the prevalence date used was 1 May 1994. To be included in the prevalence numerator, the subject had to be alive on 1 May 1994, and disease onset had to have occurred on or before this date. ${ }^{13}$ For stroke and TIA, 'lifetime' prevalence was used to describe survey-eligible people (alive on 1 May 1994) who had ever had the disease, even if neurological symptoms had been resolved.

\section{Study design and phases}

The NEDICES study was carried out in two phases. Phase 1 involved door-to-door screening of eligible people. The screening included standardized questionnaires administered by lay interviewers (social workers and student nurses). Phase 2 involved a neurologist's examination of those individuals who screened positive at the public health clinic. Home examinations were necessary for bedridden people and others with severe handicaps. 
There was no sampling in Margaritas and Arevalo county because the reference population was nearly 2000 people (adequate sample for the objectives of the study). For Lista area, a representative sample of 2000 people, stratified by age and sex, was selected from the reference population (more than 24,000 elderly people). Each eligible subject was invited to participate by mail. The contact letter explained the scope of the study, and this was followed by a telephone call to arrange an appointment for the interview. Interviewers followed special procedures for those people who were not at home (at least one direct visit was made to the subject's neighbors or relatives). If none of these strategies were effective or the subjects were too difficult to trace (e.g. because they were travelling for an extended period), an indirect screening with a surrogate respondent was attempted.

Finally, using the screening data, the neurologists, in agreement with the supervisors and interviewers, determined which subjects needed neurological examination in Phase 2 of the survey. The interviewers encouraged participation by informing the subjects that examination would be free of charge and that there would be no discomfort. The subject was asked to locate any current medication and any relevant medical documentation, and bring this with them to the examination.

\section{Standardized questionnaires applied in Phase 1 (protocols and screening instruments)}

A large questionnaire was used in Phase 1. This contained approximately 500 items assessing demographic data, health status (perceived health, main chronic diseases, functional activities in daily life, and consumption of drugs), cerebrovascular factor risks, and variables about lifestyle (consumption of alcohol, smoking habits, physical exercise, etc.).

The NEDICES protocol also included screening tools of neurological diseases. A previous pilot study (WHO-AAD project) measured the diagnostic validity of the screening instrument for dementia in 261 subjects, and results in three countries have been communicated. ${ }^{14} \mathrm{~A}$ tool of mental status (the Spanish adaptation of the Mini-Mental State Examination $^{15}$ performed by the WHO-AAD project group) and a test of functional capacity (the Spanish version of the Pfeffer scale ${ }^{16}$ ) were administered. The cut-off scores used for screening were 23/24 for the Mini-Mental test and 5/6 for the Pfeffer scale. Moreover, the WHO-ADD project group also assessed instruments for the detection of stroke,
TIA, essential tremor and PD that were used in populations with similar cultural characteristics. The three questions used for the screening of Parkinsonism were Spanish adaptations of those used in the ILSA project. ${ }^{17}$ The screening instrument for stroke was a Spanish adaptation of the questionnaire used for screening in the MONICA project. ${ }^{18,19}$

The interviewers read the questions verbatim from the questionnaire. For subjects unable to give reliable answers, the screening instrument was administered to a surrogate respondent, preferably the spouse or a sibling. A proxy respondent was also selected for subjects who died between the prevalence day (1 May 1994) and the screening day.

\section{Protocols of the clinical examination}

In Phase 2, the neurologist focused on the suspected diseases, seeking details of history, signs, symptoms, and current or past treatments. No laboratory or imaging tests were performed routinely for subjects who screened positive, but these were done for subjects with doubtful diagnoses. Resulting diagnoses, if any, could have two levels of certainty: definitive or possible. Where feasible, these diagnoses included subtype classifications. If a suspected disease was diagnosed, the neurologist had to determine the onset data.

The overall examination lasted about $30 \mathrm{~min}$. The evaluation for Parkinsonism (and essential tremor) included: (a) the motor section of the Unified Parkinson's Disease Rating Scale; ${ }^{20}$ (b) the examination of motor function and activities of daily living; (c) the Schwab and England scale; ${ }^{21}$ and (d) the Hoehn and Yahr scale. ${ }^{22}$ The evaluation for dementia included the following instruments: (a) the Mini-Mental test; ${ }^{15}$ (b) the Pfeffer scale; ${ }^{16}$ (c) a history of cognitive decline taken from family members; and (d) a semi-standardized mental examination. ${ }^{23}$ The evaluation for stroke included an evaluation of previous hospital records and imaging studies, the modified Rankin scale of daily living $^{24}$ and a standard neurological examination. To avoid conflicts with local physicians, the neurologist did not offer treatment. Instead, if the situation warranted it, the neurologist urged the subject to seek contact with their physician.

\section{Training of field staff and establishment of diagnosis agreement}

Lay interviewers performed Phase 1 . They received six to seven training sessions using videotaped interviews and were certified for the field study. In Arévalo, a few subjects who refused to answer 
the interviewers were screened directly by their primary care physicians. Three supervisors oversaw the project. One epidemiologist (RGS) supervised the organization and implementation of the entire field operation.

During Phase 2, two neurologists worked full time in Madrid (JD and CF), and another six neurologists from the '12 de Octubre' Hospital performed the neurological examinations, mainly in Arévalo. One neurologist (FBP) reviewed the doubtful cases of dementia and PD.

\section{Ethical aspects}

All participants (or the proxy of a subject with severe cognitive or sensory impairment) were asked to sign an informed consent form to participate in the survey. The study was approved by the Ethics Committee of the ' 12 de Octubre' and Princesa Hospitals. The screening interview was scheduled at the most convenient time for participants, and interviews were performed on an individual basis. Respondents were informed before the interview that the information obtained would be kept confidential. Any case of serious neurological or other illness that had not been detected previously was urgently referred to the family physician or the hospital.

\section{Results}

Fig. 1 shows the flow chart of the survey according to its phases. From 6395 people on the census, only 5914 subjects were eligible for the study (deaths before the onset of the study, 115; census errors, 58; changed address, 308; total not eligible $=481$ persons). Of these 5914 eligible subjects, 636 were not screened (deaths before the onset of Phase 1, 52; refusals, 292; unreachable, 292), 4503 were screened directly and 775 were screened indirectly for several reasons (deaths during screening phase, 156;

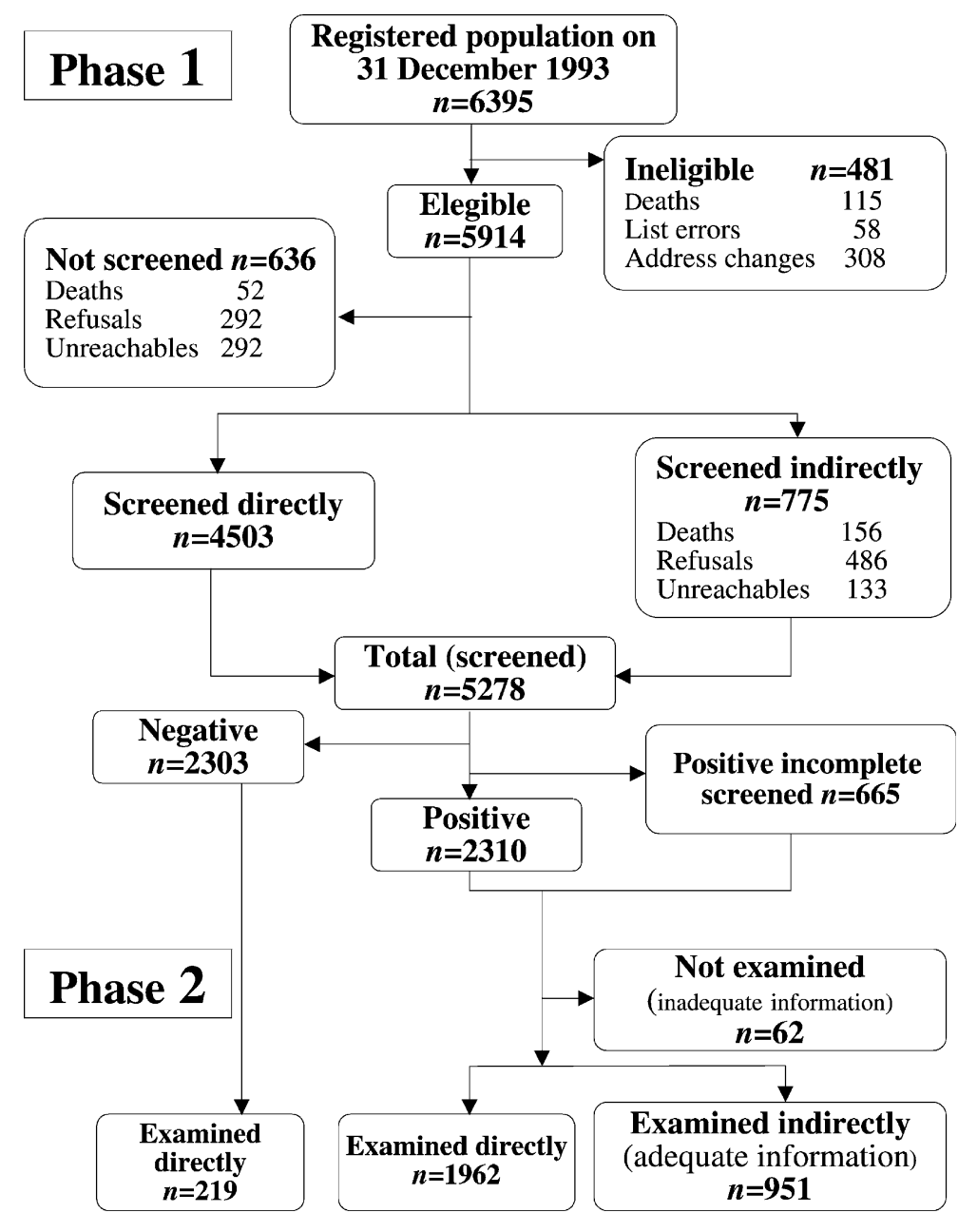

* According to revised databaseat 31/03/01. Modified from Neuroepidemiology, $2001^{25}$ to include false-negative study in Phase 2 and to review the second wave of the survey.

Figure 1 General design of the NEDICES cohort (all three areas) at its different phases*. 


\begin{tabular}{|c|c|c|c|c|c|c|}
\hline \multirow[t]{2}{*}{ Age (years) } & \multicolumn{2}{|c|}{$\begin{array}{l}\text { Elderly people } \\
\text { on census } \\
(n=6395)\end{array}$} & \multicolumn{2}{|c|}{$\begin{array}{l}\text { Eligible elders } \\
(n=5914)\end{array}$} & \multicolumn{2}{|c|}{$\begin{array}{l}\text { Screened } \\
\text { cohort } \\
(n=5278)\end{array}$} \\
\hline & Male & Female & Male & Female & Male & Female \\
\hline $65-69$ & 853 & 1073 & 808 & 1009 & 736 & 911 \\
\hline $70-74$ & 701 & 945 & 673 & 889 & 623 & 788 \\
\hline $75-79$ & 480 & 688 & 437 & 641 & 404 & 555 \\
\hline $80-84$ & 342 & 582 & 305 & 533 & 279 & 460 \\
\hline $85-89$ & 195 & 329 & 165 & 283 & 151 & 236 \\
\hline$>89$ & 72 & 135 & 58 & 113 & 45 & 90 \\
\hline Total & 2643 & 3752 & 2446 & 3468 & 2238 & 3040 \\
\hline
\end{tabular}

\begin{tabular}{|c|c|c|c|c|c|c|}
\hline \multirow[t]{2}{*}{ Age (years) } & \multicolumn{2}{|c|}{$\begin{array}{l}\text { Lista } \\
(n=1566)\end{array}$} & \multicolumn{2}{|c|}{$\begin{array}{l}\text { Arévalo } \\
(n=1937)\end{array}$} & \multicolumn{2}{|c|}{$\begin{array}{c}\text { Margaritas } \\
(n=1775)\end{array}$} \\
\hline & Male & Female & Male & Female & Male & Female \\
\hline $65-69$ & 213 & 302 & 258 & 284 & 265 & 325 \\
\hline $70-74$ & 139 & 226 & 286 & 290 & 198 & 272 \\
\hline $75-79$ & 123 & 170 & 161 & 187 & 120 & 198 \\
\hline $80-84$ & 88 & 125 & 110 & 169 & 81 & 166 \\
\hline $85-89$ & 55 & 75 & 58 & 88 & 38 & 73 \\
\hline$>89$ & 20 & 30 & 14 & 32 & 11 & 28 \\
\hline Total & 638 & 928 & 887 & 1050 & 713 & 1062 \\
\hline
\end{tabular}

refusal, 486; unreachable, 133) by means of proxy or their general practitioner. In total, 2238 males and 3040 females were screened by both approaches. We obtained adequate information about the neurological disorders under study in 5216 subjects. Table 1 shows the distribution of elderly people by age and sex according to the census, eligible and screened populations.
The overall refusal rate was $14.7 \%$; the lowest refusal rate was in Margaritas $(12.8 \%$ ), (Lista $(15.1 \%)$ and Arévalo $(16.4 \%))$, and females were more likely than males to refuse in all three sites, as were older subjects. Table 2 shows the distribution of screened people in each area.

We obtained information about the educational level of 5231 screened people $(99.1 \%)$. Table 3 shows the educational level by age and sex. The greatest educational level was in Lista area (Table 4). Table 5 shows the occupation of 4095 subjects according to the main categories established by the Spanish National Statistics Institute, ${ }^{24}$ reported as the occupation that the subject had been employed in for the longest period of time in their lifespan. Of the 4958 elderly people who answered questions about their subjective health status, nearly $60 \%$ perceived themselves to be in good general health. General data about living arrangements and health status are shown in Table 6.

\section{Discussion}

The aim of this study was to establish a specific Spanish cohort of elderly people dwelling in three communities of central Spain, and to estimate incidence data and risk factors of several neurological disorders (dementia, PD and essential tremor, and stroke and TIA) over 3 years. For this purpose, we focused on three geographical areas with different cultural and sociodemographic characteristics. According to the results on education and occupation, this survey offered three cohorts with different lifestyles. The majority of people dwelling in Lista had a higher level of education than in the other two areas, and were exposed to different occupational risk factors: white-collar vs blue-collar workers.

\begin{tabular}{|c|c|c|c|c|c|c|c|c|}
\hline \multirow[t]{2}{*}{ Age (years) } & \multicolumn{2}{|c|}{ Illiterate $(n=711)$} & \multicolumn{2}{|c|}{$\begin{array}{l}\text { Less than primary } \\
\text { school }^{*}(n=2092)\end{array}$} & \multicolumn{2}{|c|}{$\begin{array}{l}\text { Primary } \\
\operatorname{school}^{\mathrm{a}}(n=1720)\end{array}$} & \multicolumn{2}{|c|}{$\begin{array}{l}\text { Secondary or more } \\
(n=708)\end{array}$} \\
\hline & Male & Female & Male & Female & Male & Female & Male & Female \\
\hline $65-69$ & 54 & 130 & 299 & 376 & 236 & 286 & 145 & 112 \\
\hline $70-74$ & 50 & 121 & 252 & 292 & 223 & 283 & 94 & 84 \\
\hline $75-79$ & 27 & 95 & 158 & 215 & 153 & 187 & 66 & 51 \\
\hline $80-84$ & 22 & 99 & 118 & 180 & 83 & 128 & 51 & 48 \\
\hline $85-89$ & 19 & 59 & 62 & 92 & 43 & 66 & 25 & 17 \\
\hline$>89$ & 7 & 28 & 19 & 29 & 8 & 24 & 9 & 6 \\
\hline Total & 179 & 532 & 908 & 1184 & 746 & 974 & 390 & 318 \\
\hline
\end{tabular}

*Literate but without certification of primary school education.

a People with certification of primary school education. 
Table 4 Distribution of the educational level in the three sites of the NEDICES cohort.

\begin{tabular}{|c|c|c|c|c|c|c|}
\hline \multirow[b]{2}{*}{ Levels } & \multicolumn{2}{|l|}{ Lista } & \multicolumn{2}{|c|}{ Arévalo } & \multicolumn{2}{|c|}{ Margaritas } \\
\hline & $n$ & $\%$ & $n$ & $\%$ & $n$ & $\%$ \\
\hline Illiterate & 23 & 1.5 & 281 & 14.6 & 407 & 22.9 \\
\hline Less than primary school* & 615 & 40.3 & 543 & 28.1 & 934 & 52.6 \\
\hline Primary school ${ }^{\mathrm{a}}$ & 369 & 24.2 & 1086 & 56.3 & 265 & 14.9 \\
\hline Secondary or more & 520 & 34.0 & 19 & 1.0 & 169 & 9.6 \\
\hline Total & 1527 & 100.0 & 1929 & 100.0 & 1775 & 100.0 \\
\hline
\end{tabular}

Moreover, we were able to obtain adequate information about the majority of eligible elderly people from official records: census and medical files. The authorities of each municipality provided a computer-based list of all residents from their LRO. The registration in Spain has important social and fiscal implications such as voting and tax filing. A person can remain a resident when temporarily out of the municipality until a formal request for transfer of residence is filed. On the other hand, health care in all three sites is provided by the National Health Service (NHS), and this is free (medical attention, hospitalization and prescriptions) for elderly people. Even elderly people using private medical care generally refer to NHS physicians to obtain free medication.

We calculated that a cohort of nearly 2000 people was necessary in each location according to the incidence rate of PD (the rarest of the neurological diseases studied) with $95 \%$ confidence intervals, and estimating a 15-20\% annual withdrawal. ${ }^{25}$ In addition, we selected a two-phase

Table 5 Occupation/employment of the screened cohort $(n=4095)^{*}$.

\begin{tabular}{llr}
\hline & Cases & $\%$ \\
\hline Never employed & 3 & 0.1 \\
Managers & 54 & 1.3 \\
Skilled professionals & 221 & 5.4 \\
Semi-skilled professionals & 72 & 1.8 \\
Administrative workers & 231 & 5.6 \\
Service sector workers & 265 & 6.5 \\
Agriculture and fishing workers & 844 & 20.6 \\
Skilled workers & 599 & 14.6 \\
Machine operators & 68 & 1.7 \\
Unskilled workers (and cleaners) & 1685 & 41.1 \\
Military workers & 53 & 1.3 \\
Total & 4095 & 100.0 \\
\hline *The employment categories were reported as the occupation \\
that the subject was employed in for the longest duration in \\
their lifetime. Categorization of occupation according to \\
recommendations of the Spanish National Statistics Institute \\
('Instituto Nacional de Estadística'-INE from Spain). \\
\hline
\end{tabular}

approach to ascertain the prevalence of the chronic neurological disorders chosen. ${ }^{10}$ This two-phase design is quite justified when the sensitivity of screening tools of studied disorders is adequate, as shown by the pilot study of the WHO-ADD project. ${ }^{14}$

The first wave of the NEDICES cohort showed a high participation rate, that was similar ${ }^{26,27}$ or higher than seen in other longitudinal studies on ageing (a non-response rate near $20 \%{ }^{28-30}$ or $30 \%^{31-33}$. This low non-response could be explained by the recruiting procedure of the NEDICES study: review of the census by means of official files; local announcements by newspapers, radio and television; repeated contacts (included home visits) with the subjects or their proxies (relatives, neighbors and general practitioners); special procedures used by trained interviewers to obtain additional information about the subjects and to ensure that they

\begin{tabular}{lll}
$\begin{array}{l}\text { Table } 6 \text { Demographic and general health data } \\
\text { screened cohort. }\end{array}$ & \\
\hline & Cases & $\%$ \\
Marital status & & \\
Single & 401 & 9.6 \\
Married & 2484 & 59.5 \\
Separated/divorced & 67 & 1.6 \\
Widowed & 1223 & 29.3 \\
Total & 4175 & 100.0 \\
Living arrangement & & \\
Alone & 647 & 15.7 \\
With one or more persons & 3359 & 81.6 \\
Institutionalized & 77 & 1.9 \\
Others (rotate among relatives) & 34 & 8 \\
Total & 4117 & 100.0 \\
Subjective health & & \\
Very good & 507 & 10.2 \\
Good & 2344 & 47.3 \\
Average & 1473 & 29.7 \\
Bad & 483 \\
Very bad & 151 & 9.7 \\
Total & 3.0 \\
Number of diseases $(\mathrm{n}=4449)^{*}$ & $2.53(1.61)$ \\
Number of drugs consumed $(\mathrm{n}=5011)^{*}$ & $2.13(1.74)$ \\
\hline *Mean (SD). & \multicolumn{2}{l}{100.0} \\
\hline
\end{tabular}


were not mistaken for door-to-door salespersons; and the guaranteed comfortable environment for the interview and medical examination. Nevertheless, the refusal rate was higher in older women but with a similar percentage to that found in other neuro-epidemiological studies. ${ }^{34,35}$ Despite the higher non-response rate in the rural setting, we obtained adequate information about all participants through their family doctors.

Despite these differences in participation rates, all three areas had a similar distribution of age group and sex. The total population of this survey is not, obviously, representative of the whole elderly population of Spain. Nevertheless, the rural area is representative of the rural areas of central Spain, and the two urban areas represent the poor and rich areas of a big Spanish city, according to the rules of statistical inferences. ${ }^{36}$ Despite not being representative, these cohorts have shown similar sociodemographic characteristics of other Spanish studies based on elderly populations. ${ }^{37,38}$ Moreover, the percentages of people screened in each age group are similar to the Spanish elderly populations in 1993: $65-74$ years, $59.6 \%$ vs $57.9 \%$; $75-84$ years, $31.4 \%$ vs $32.2 \%$; and 84 years and over, $9.9 \%$ vs $8.9 \% .{ }^{39}$

With the abovementioned methodology, we obtained suitable information (for the neurological disorders investigated) for the majority of eligible subjects $(87.9 \%)$ in a large-scale elderly population from well-defined communities of central Spain. Survey attributes of Phase 2 established that each individual who screened positive was to be examined, but this was not always possible to accomplish. A great effort was made to keep such losses to a minimum. The survey team attempted to avoid long lapses of time between screening and examination. Also, the survey supervisor, general practitioner or subjects who had been examined previously were enlisted to seek the co-operation of those who refused examination. When the examination could not be performed, relevant medical information was sought from close relatives of the subjects and from general practitioners to obtain adequate information about the neurological disorders studied.Taking account of the distribution of screened subjects by education and occupation, the NEDICES cohort has shown a sufficient variety of lifestyles to compare different risk factors of neurological disorders in the second wave of this longitudinal study. Furthermore, the sample showed similar numbers of chronic diseases and drug consumption to other Spanish studies. ${ }^{37,38,40-42}$ Therefore, we consider the NEDICES cohort to be a large baseline survey that will improve our knowledge of incidence rates of the neurological diseases studied and their risk factors in Spain.

\section{Acknowledgements}

The NEDICES study was supported through grants from the World Health Organization Age-Associated Dementia Project (WHO-AAD), the EPICARDIAN study, PB1225-C04 and ASTA Medica (videotaping of Parkinsonian patients), and official Spanish Research Agencies (FIS 93/0773, CAM 94/0032).

\section{References}

1. Bermejo FP, Tolosa ES. Epidemiología de las enfermedades neurológicas en el anciano (Neuroepidemiology in elderly populations). In: Grupo de Trabajo de Enfermedades del Envejecimiento, editor. Epidemiología del Envejecimiento en España (Epidemiology of Ageing in Spain). Madrid: Fondo de Investigaciones Sanitarias. Ministerio de Sanidad y Consumo; 1990. p. 79-88.

2. Bermejo FP. Nivel de Salud y Deterioro Cognitivo en los Ancianos (Health Status and Cognitive Impairment in the Elders). Madrid: Díaz de Santos; 1993.

3. Coria F, Gómez del Caso JA, Mínguez L, Rodríguez-Artalejo F, Clavería LE. Prevalence of age-associated memory impairment and dementia in a rural community. $J$ Neurol Neurosurg Psychiat 1993;56:973-6.

4. Matias-Guiu J. Neuroepidemiología (Neuroepidemiology). Barcelona: Prous Edit; 1993.

5. Matías-Guiu J, Oltra A, Falip R, et al. Occurrence of transient ischemic attacks in Alcoi: descriptive epidemiology. Neuroepidemiology 1994;13:34-9.

6. LópezPousa S, Vilalta JF, Llinas JR. Prevalencia de la enfermedad vascular cerebral en España: estudio en un área rural en Girona (Prevalence of cerebrovascular disease in Spain: a study in a rural area of Girona). Rev Neurol 1995; 23:1081-6.

7. Lobo A, Saz P, Marcos G, Día JL, De-La-Cámara C. The prevalence of dementia and depresion in the elderly community in a Southern European population. The Zaragoza study. Arch Gen Psychiatr 1995;52:497-506.

8. Manubens JM, Martínez-Lage JM, Lacruz F, et al. Prevalence of Alzheimer's disease and other dementing disorders in Pamplona, Spain. Neuroepidemiology 1995;14: 155-64.

9. Pi J, Olivé JM, Roca J, Masana J. Prevalence of dementia in a semi-rural population of Catalunya, Spain. Neuroepidemiology 1996;15:33-41.

10. Anderson DW, Kalton G. Case-finding strategies for studying rare chronic diseases. Ital J Appl Stat 1990;2:309-21.

11. Amaducci L, Baldereschi M, Amato MP, et al. The World Health Organisation cross-national research program on age associated dementias. Aging 1991;3:89-96.

12. Gabriel R, Bermejo FP, Vega S, et al. Survey of cardiovascular disease (acute myocardial infarction and stroke) and its risk factors in the elderly population of Spain: the EPICARDIAN study. Methods and demographic findings. CVD Prev 1999;2:290-300.

13. Last JM, Abramson JH, Friedman GD, Porta M, Spasoff RA, Thuriaux M, editors. A Dictionary of Epidemiology, 3rd ed. New York: Oxford University Press; 1995.

14. Baldereschi M, Meneghini F, Quiroga P, et al. Cognitive versus functional screening for dementia across different countries: cross-cultural validation of the Mini-Mental State Examination 
(MMSE) and the Pfeffer activities questionnaire (PFAO) against the standardised clinical diagnosis of dementia. Neurology 1994;44(Suppl 2):A365.

15. Folstein MF, Folstein SE, Mchugh PR. Mini-Mental State. A practical method for grading the cognitive state of patients for the clinician. J Psychiat Res 1975;12:189-98.

16. Pfeffer RI, Kerosaki TT, Harrah CH, Chance JM, Filos S. Measurement of functional activities in older adults in community. Gerontology 1982;37:323-9.

17. Consiglio Nazionale delle Ricerche, Studio Longitudinale Italiano Sull'Invecchiamento (ILSA). Strumenti Epidemiologici, Firenze: Centro SMID; 1992.

18. Bamford J, Sandercock P, Dennis M, Burn J, Warlow C. A prospective study of acute cerebrovascular disease in the community. The Oxfordshire Community Stroke Project 1981-1986. 2. Incidence, case fatality rates and overall outcome at one year of cerebral infarction, primary intracerebral and subarachnoid haemorrhage. J Neurol Neurosurg Psychiatr 1990;53:16-22.

19. WHO MONICA project, Monica Manual. Geneva: World Health Organization; 1990.

20. Fahn S, Elton RL. In: Fahn S, Marsden CD, Goldtein M, Calne $\mathrm{DB}$, editors. Recent Developments in Parkinson's Disease, vol. 2. New Jersey: Florham Park; 1987. p. 153-63.

21. Schwab RS, England AC. Projection technique for evaluating surgery in Parkinson's disease. In: Gillinghamn FJ, Donaldson IML, editors. Third Symposium in Parkinson's Disease. Edinburgh: Churchill Livingstone; 1969. p. 152-7.

22. Hoehn MM, Yahr MD. Parkinsonism: onset, progression, and mortality. Neurology 1967;17:427-42.

23. Bermejo F, Alom J, Peña-Casanova J, et al. Registro multicéntrico de casos incidentes de demencia. Un estudio del grupo de demencias de la Sociedad Española de Neurología (Multicentric register of index cases of dementia. A study by the Spanish Neurological Society's Dementia Group). Neurología 1994;9:401-6.

24. Instituto Nacional de Estadística, Clasificación Nacional de Ocupaciones 1994 (CNO-94) (National Classification on Occupations 1994). Madrid: Instituto Nacional de Estadística; 1994.

25. Bermejo F, Gabriel R, Vega S, Morales JM, Rocca WA Anderson DW. for the Neurological Disorders in Central Spain (NEDICES) Study Group. Problems and issues with door-todoor, two-phase surveys: an illustration from Central Spain. Neuroepidemiology 2001;20:225-31.

26. Cornoni-Huntley J, Brock DB, Ostfeldt AM, Taylor JO, Wallace RB, Laferry ME, editors. Establish Population for Epidemiological Studies of the Elderly, Resource Data Book. NIH Publication No. 86-2443. Washington, DC: US Government Printing Office; 1986.

27. Mossey JM, Havens B, Roos NP, Shapiro E. The Manitoba longitudinal study on aging: description and methods. Gerontologist 1981;21:551-8.

28. Guralnik JM, Kaplan GA. Predictors of health aging: prospective evidence from the Alameda County Study. Am J Public Health 1989;79:703-8.

29. Hanson BS, Isacsson V, Janzon L, Lindell S. Social network and social support influence mortality in elderly men. $A m \mathrm{~J}$ Epidemiol 1989;130:100-11.
30. Hofman A, Grobbee DE, de Jong PT, van den Ouweland FA. Determinants of disease and disability in the elderly: the Rotterdam Elderly Study. Eur J Epidemiol 1991;7: 403-22.

31. Simons LA, McCallum J, Friedlander Y, Simons J, Powell I, Heller R. Dubbo study of the elderly: sociological and cardiovascular risk factors at entry. Aust NZ J Med 1991; 21:701-9.

32. Dartigues JF, Gagnon M, Michel P, et al. Le programme de recherche Paquid sur l'épidémiologie de la démence. Méthodes et résultat initiaux (Research Paquid programme on epidemiology of dementia. Methods and preliminary results). Rev Neurol (Paris) 1991;147:225-30.

33. Pijls LT, Feskens EJ, Kromhout D. Self-rated health, mortality, and chronic diseases in elderly men. The Zutphen Study, 1985-1990. Am J Epidemiol 1993;138: $840-8$.

34. Reggio A, Rocca WA, Patti F, et al. Prevalence of stroke: a door-to-door survey in three Sicilian municipalities. Sicilian Neuroepidemiologic Study (SNES) Group. Neuroepidemiology 1996;15:92-102.

35. Anderson DW, Rocca WA. Case ascertainment uncertainties in prevalence surveys of Parkinson's disease. Mov Disord 1998;13:626-32.

36. Deming WE. Boundaries and statistical inference. In: Johnson NL, Smith H Jr., editors. New Developments in Survey Sampling. New York: Wiley Interscience; 1969. p. 652-70.

37. Perula de Torres LA, Martínez de la Iglesia J, Espejo JC. Estado de salud de la población mayor de 60 años y su relación con factores sociodemográficos (proyecto ANCO) (Health status of the over 60 years of age population and its relationship with sociodemographic factors-ANCO Project). Aten Primaria 1997;20:425-34.

38. Damian J, Ruigomez A, Pastor V, Martín-Moreno JM. Determinants of self assessed health among Spanish older people living at home. J Epidemiol Commun Health 1999;53: $412-6$.

39. Instituto Nacional de Estadísticas, Proyecciones de la Población de España Calculada a Partir del Censo de Población de 1991. Total Nacional 1990-2020 (Projections of Populations in Spain Calculated by 1991 Census. National results 1990-2020, Madrid: Instituto Nacional de Estadística; 1995.

40. León VG, Zunzunegui MV, Béland F. El diseño y ejecución de la encuesta Envejecer en Leganés (Design and conducting of the survey Envejecer en Leganés). Rev Gerontol 1995; 5(Suppl 4):215-31.

41. Vega S, Lopez-Gay L, Bermejo FP, et al. Consumo de fármacos en población mayor de 60 años en una zona rural (Drug consumption by people over 60 years of age in a rural area). Aten Primaria 1996;17:496-500.

42. Fernández Merino MC, Verez Vivero L, Gude Sampedro F. Morbilidad crónica y autopercepción de salud en los ancianos de una comunidad rural (Chronic morbidity and selfperception of health in the elder of a rural community). Aten Primaria 1996;17:108-12. 